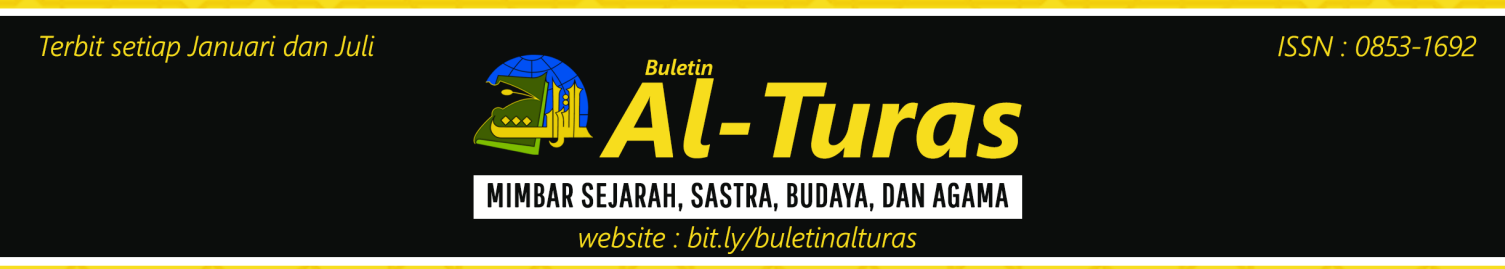

\title{
Hibriditas Kolonial Dan Nilai Pendidikan Karakter Pada Novelet Dorodasih Karya Imam Budhi Santosa
}

\author{
Riska Dewi Widyaningrum ${ }^{I}$
}

\begin{abstract}
This study aims to (1) describe and explain the colonial hybridity Dorodasih novella by Imam Budhi Santosa, and (2) to describe the value of character education at Dorodasih novella by Imam Budhi Santosa. This study used a qualitative descriptive method to describe the hybridity and the educational value of the character in the novella Dorodasih of Imam Budhi Santosa. The data in this study of words, phrases, sentences contained in Dorodasih novella by Imam Budhi Santosa, published by Reader Literature LKIS Yogyakarta. Data collection techniques used in this study is a non-interactive technique. Mechanical noninteractive done by intensive reading of the novella and make record actively with content analysis. The validity of the data used to use data triangulation to collect the same data. In a sense the same or similar data will be valid truth when used several different data sources. The conclusions from the results of this study as follows: (1) the existence of the colonial hybridity Dorodasih novella by Imam Budhi Santosa, and (2) the value of character education that existed at novelet Dorodasih is hard work.
\end{abstract}

Keywords: Character Education, Colonial Hybridity, Dorodasih, Identity, Post-colonial,

Abstrak
Penelitian ini bertujuan untuk (1) mendeskripsikan dan menjelaskan hibriditas kolonial pada novelet Dorodasih karya Imam Budhi Santosa, dan (2) mendeskripsikan nilai pendidikan karakter pada novelet Dorodasih karya Imam Budhi Santosa. Penelitian ini menggunakan metode deskriptif kualitatif untuk mendeskripsikan hibriditas dan nilai pendidikan karakter dalam novelet Dorodasih karya Imam Budhi Santosa. Data dalam penelitian ini berupa kata, frasa, kalimat yang terdapat dalam novelet Dorodasih karya Imam Budhi Santosa, yang diterbitkan oleh Pustaka Sastra LKIS Yogyakarta. Teknik pengumpulan data yang digunakan dalam penelitian ini adalah teknik noninteraktif. Teknik nonintteraktif dilakukan dengan melakukan pembacaan secara intensif dari novelet dan melakukan pencatatan secara aktif dengan metode content analysis. Validitas data yang digunakan menggunakan trianggulasi data untuk mengumpulkan data yang sama. Dalam arti data yang sama atau sejenis akan lebih valid kebenarannya apabila digunakan beberapa sumber data yang berbeda. Simpulan dari hasil penelitian ini sebagai berikut: (1) adanya hibriditas kolonial pada novelet Dorodasih karya Imam Budhi Santosa, dan (2) nilai pendidikan karakter yang ada pada novelet Dorodasih adalah kerja keras.

Kata Kunci: Hibriditas Kolonial, Identitas, Novelet Dorodasih, Pendidikan Karakter, Postkolonial 


\section{A.Pendahuluan}

Sejarah kolonial adalah sejarah perampasan. Kisah tentang perebut tanah penghasil roti, padi, martabat, dan pemupuk prangsangka-prasangka rasial serta status sosial. Begitu pula dengan Indonesia yang dulu dikenal sebagai Hindia Belanda memiliki sejarah panjang penuh dengan konflik kolonialisme. Masa kejayaan kolonial yang terus berlangsung mengakibatkan penderitaan bangsa Indonesia selama 3,5 abad yang lalu. Bekas-bekas penjajahan kolonial berlangsung hingga sekarang. Representasi dari realitas kehidupan dapat dituangkan dalam berbagai media. Salah satunya yaitu seni sastra tulis. Gambaran sejarah bangsa Indonesia sering kali diabadikan dalam sebuah cerita sebagai dokumentasi sejarah.

Sejalan dengan hal tersebut sastra Indonesia sebagai suatu yang dipelajari atau pengalaman manusia yang dapat disumbangkan untuk renungan dan penilaian. Disamping melatih keterampilan berbahasa, sastra dapat menambah pengetahuan tentang pengalaman hidup manusia, membantu mengembangkan pribadi, pembentukan watak, memberi kepuasan batin, kenyamanan, dan meluaskan dimensi kehidupan. Nurgiyantoro (2005:3) menyatakan bahwa fiksi merupakan hasil dialog, kontemplasi, dan reaksi pengarang terhadap lingkungan dan kehidupan.

Objek penelitian ini adalah novelet Dorodasih karya Imam Budhi Santosa. Novelet Dorodasih yang menceritakan perempuan sederhanayang tidak tamat SMA. Kesederhanaannya dalam bersikap, namun tidak dalam bercita-cita. Perempuan Dorodasih menggambarkan kekuatan, tekad, sekaligus kelemahan manusia yang setiap kali harus tenggelam dulu ke jurang kebodohan untuk menjadi baik. Cerita dalam novelet Dorodasih karya Imam Budhi Santosa mengambil latar belakang kehidupan pemetik teh. Novelet ini dibuat berdasarkan kenangan penulis yang pernah bekerja di perkebunan teh daerah Kendal, Semarang. Novelet ini baik untuk dikaji karena pada tahun 1994, 1995, 1997 menjadi pemenang sayembara Lomba Cerber yang diadakan oleh Majalah Femina. Selain itu, realita yang disajikan oleh penulis dapat menambah gambaran konflik perjalanan manusia.

Adapun argumentasi peneliti dalam ketertarikannya melakukan penelitian terhadap novelet Dorodasih karya Imam Budhi Santosa; (1) novelet ini memiliki peniruan identitas dilihat dari mekanisme pekerjaan pada zaman kolonial; (2) novelet ini memiliki cerita yang bisa memotivasi pembaca melalui cerita-cerita yang dihadirkan, (3) cerita dalam novelet ini memiliki nilai pendidikan karakter yang dominan sehingga cocok untuk pembelajaran. Penelitian ini bertujuan untuk (1) mendeskripsikan dan menjelaskan identitas kolonial pada novelet Dorodasih karya Imam Budhi Santosa, dan (2) mendeskripsikan dan menjelaskan nilai pendiidkan karakter.

Karya sastra dapat dilihat dan dinilai dalam berbagai bentuk. Beberapa bentuk karya sastra diantaranya adalah berupa puisi, prosa, dan drama. Prosa dapat berupa cerpen, novel, dan novelet. Cerpen dan novel adalah bentuk karya 
sastra yang populer di Indonesia dan hampir semua orang mengetahuinya. Akan tetapi, banyak masyarakat yang belum mengetahui tentang bentuk karya sastra berupa novelet. Unsur-unsur yang ada dalam novelet sama dengan unsur-unsur yang ada dalam novel dan cerpen. Novelet merupakan salah satu bentuk karya sastra fiksi yang tergolong prosa naratif yang mengandung unsur ekstrinsik dan intrinsik yang membangunnya. Novelet juga dapat diartikan sebagai cerita berbentuk prosa yang panjangnya antara cerpen dan novel.

Teori yang digunakan dalam menganalisis unsur-unsur yang ada dalam novelet sama dengan teori yang digunakan dalam menganalisis unsurunsur yang ada dalam novel. Hal ini karena keduanya sama-sama merupakan karya sastra berbentuk prosa. Menurut Santosa (2010:46) novelet dapat diartikan sebagai suatu karangan atau karya yang lebih pendek dari pada roman, tetapi jauh lebih panjang dari pada cerita pendek, yang isinya hanya mengungkapkan suatu kejadian yang penting, menarik dari kehidupan seseorang secara singkat dan yang pokok-pokok saja.

Novelet merupakan novel yang pendek atau cerpen yang panjang. Sementara itu, Nurgiyantoro (2005: 10) mengemukakan adanya persamaan dan perbedaan antara novel dan cerpen. Novel dan cerpen sebagai karya sastra mempunyai persamaan, keduanya dibangun oleh unsur-unsur pembangun yang sama, dan keduanya dibangun oleh unsur intrinsik dan ekstrinsik. Novel dan cerpen sama-sama memiliki unsur peristiwa, plot, tema, tokoh, latar, sudut pandang, dan lain-lain. Oleh karena itu, novel dan cerpen dapat dianalisis dengan pendekatan yang kurang lebih sama. Namun demikian, terdapat perbedaan intensitas yaitu panjang pendeknya cerita, gaya penceritaan novel lebih mendalam dan luas dibanding cerpen, dan unsur pembangun novel lebih rinci serta kompleksitasnya dibandingkan dengan unsur-unsur pembangun cerpen. Berdasarkan beberapa pendapat dapat disimpulkan bahwa novelet dan novel dapat dikatakan sama karena keduanya sama-sama memiliki plot (alur) yang panjang dan didalamnya sama-sama memiliki permasalahan yang bersifat kompleks

Barry (2010: 227) situasi postkolonial menghadirkan identitas ganda atau hibrid dan terdapat tahapantahapan dalam hibiditas, antara lain; (a) adopt/mengadopsi, karena ambisi penulis adalah untuk mengadopsi bentuk sebagai tempat berpijaknya, (b) adapt/ adaptasi, karena tujuannya adalah untuk mengadaptasi bentuk dari koloni, dan (c) Adept/ mahir, karena karakternya adalah asumsi bahwa penulis kolonial 'mahir' secara mandiri dalam perihal bentuk.

Hibiditas menurut Ratna
(2008:119) menggunakan istilah mongrel, bahwa hibiditas dapat diartikan adanya hubungan dua kebudayaan dengan identitas yang berbeda. Kaum penjajah maupun terjajah sering kali meniru pola kebudayaan, hanya saja kesan yang berbeda yang menegaskan keinginan merdeka bagi kaum terjajah. Selaras dengan Ryan (2011: 268) menegaskan bahwa identitasnya bersifat hibrid karena mereka terdiri dari dua atau lebih untaian berbeda yang saling berjalinan. Jadi, hibriditas 
mengacu pada transkultur baru akibat adanya kolonialisasi serta menganalisis hubungan antara penjajah dengan pihak terjajah, sehingga menimbulkan pertukuran budaya. Peniruan terhadap budaya dominan menjadi strategi untuk merongrong hegemoni kolonial.

Betapa pentingnya pendidikan dan pembangunan karakter pada masa saat ini, karena pendidikan dan pembangunan tanpa karakter sesungguhnya tidaklah banyak berarti - Karakter dianggap sangat urgen dan bahkan segala sesuatunya harus berbasis karakter yang baik sesuai hakikat manusia sebagai ciptaan Tuhan Yang Maha Sempurna dan Maha Mulia. Karakter dapat dimaknai sebagai nilai dasar positif yang dimiliki seseorang, yang membedakannya dengan orang lain serta diwujudkan dalam perilakunya sehari-hari.

Sejalan dengan pengertian karakter, menurut Ki Hajar Dewantara menyatakan bahwa pendidikan adalah daya upaya untuk memajukan bertumbuhnya budi pekerti (kekuatan batin, karakter), pikiran (intellect) dan tubuh anak. Pendidikan juga dapat diartikan sebagai upaya sadar dan terencana dalam proses pembimbingan dan pembelajaran bagi individu agar tumbuh berkembang menjadi manusia yang mandiri, bertanggung jawab, kreatif, berilmu, sehat dan berakhlak (berkarakter) mulia (UU No.20 tahun 2003).

Menurut Aunillah (2011:18) pendidikan karakter adalah sebuah sistem yang menanamkan nilai-nilai karakter pada peserta didik, yang mengandung komponen pengetahuan, kesadaran individu, tekad, serta adanya kemauan dan tindakan untuk melaksanakan nilai-nilai, baik terhadap Tuhan Yang Maha Esa, diri sendiri, sesama manusia, lingkungan, maupun bangsa, sehingga akan terwujud insan kamil. Pendidikan diarahkan untuk membantu dalam meningkatkan sumberdaya manusia sebagai pendukung utama dalam pembangunan bangsa. Untuk memenuhi sumberdaya manusia tersebut, maka pendidikan memegang peranan yang penting. Oleh karena itu, pendidikan nasional mengemban misi untuk membentuk manusia sempurna (insan kamil). Dibutuhkan sistem pendidikan (kurikulum) yang memiliki materi yang holistik serta ditopang oleh pengelolaan dan pelaksanaan yang baik.

\section{Kementerian Pendidikan}

Nasional (sekarang Kementerian Pendidikan dan Kebudayaan) telah merumuskan 18 nilai karakter yang akan ditanamkan dalam diri para siswa sebagai upaya untuk membangun karakter bangsa (Suyadi, 2013: 7). Berdasarkan buku Pengembangan Pendidikan Budaya dan Karakter Bangsa yang disusun Kemendiknas (2010), ke-18 nilai pendidikan karakter yang dimaksud meliputi religius, jujur, toleransi, disiplin, kerja keras, kreatif, mandiri, demokratis, rasa ingin tahu, semangat kebangsaan, cinta tanah air, menghargai prestasi, bersahabat/komunikatif, cinta damai, gemar membaca, peduli lingkungan, peduli sosial, dan tanggung jawab.

Novelet Dorodasih menyajikan nilai pendidikan karakter yang dapat digunakan sebagai tuntunan masyarakat atau penikmat karya sastra dan para kaum pelajar untuk cerminan kehidupan, seperti jujur, disiplin, kerja keras, 
mandiri, rasa ingin tahu, peduli sosial, dan sebagainya. Nilai- nilai pendidikan karakter dalam Novelet Dorodasih tersebut terbentuk karena adanya konflik batin perempuan karena ruang lingkup pekerjaan yang masih semenahmenah dan tidak memperdulikan nasib bawahan. Peristiwa dalam novelet tersebut terbentuk berdasarkan caracara kolonial dalam memperlakukan bawahan. Sikap tersebut ditunjukkan oleh kaum superioritas terhadap kaum inferioritas dari pihak kolonial.

Penelitian ini merupakan penelitian deskriptif kualitatif dengan menggunakan pendekatan postkolonial. Data dalam penelitian ini berupa teks yang berasal dari novelet Dorodasih karya Imam Budhi Santosa. Teknik pengumpulan data menggunakan teknik pengumpulan data noninteraktif dengan content analysis (analisis isi) dan wawancara informan. Kegiatan yang dilakukan adalah membaca, mencermati, menafsirkan dan menganalisis novelet Dorodasih karya Imam Budhi Santosa. Teknik validitas data dengan triangulasi data dan sumber. Teknik analisis data menggunakan analisis model interaktif.

\section{B. Pembahasan}

Pada bagian ini diuraikan mengenai pembahasan terhadap penelitian novelet Dorodasih karya Imam Budhi Santosa. Berdasarkan hasil penelitian dapat diuraikan sebagai berikut.

\section{Peniruan Identitas Kolonial}

Beranjak dari peristiwa kontak kedua bangsa yaitu bangsa terjajah dan penjajah tidak lepas dari adanya kebiasaan-kebiasaan yang dilakukan.
Baik dari cara berpikir, bertindak, cara berpakaian, sarana transportasi, dan bahasa. Kebiasaan kedua bangsa dalam berinteraksi menciptakan adanya identitas ganda dan peniruan. Identitas kolonial mulai ditiru tentunya setelah masa penjajahan. Selain itu, pendominasian dan pengeksploitasian budak atau kuli bawahan digambarkan pada novelet Dorodasih karya Imam Budhi Santosa. Berikut kutipan yang menjelaskan hal tersebut.

\begin{tabular}{|c|}
\hline $\begin{array}{l}\text { Bagaimana tidak? Me } \\
\text { anyalah rendahan. Is } \\
\text { erusahaannya, karya } \\
\text { orong tetap. Tapi sebenar } \\
\text { ahasanya saja yang diperh } \\
\text { asib dan statusnya be } \\
\text { anyak berubah. Masih se } \\
\text { ali onderneming di za } \\
\text { elanda dulu. Kasarnya, t }\end{array}$ \\
\hline
\end{tabular}

Berdasarkan kutipan tersebut, disampaikan pada awal cerita ketika pengarang menyampaikan bahwa pemetik teh sama halnya dengan kuli bawahan atau onderneming zaman Belanda. Hal itu jelas adanya pembeda status antara atasan dengan kuli bawahan. Konteks dalam cerita 
Dorodasih yang menyoroti kehidupan pemetik teh memperlihatkan identitas kolonial yang masih melekat pada sistem kerjanya. Dominasi kekuasaan atasan memperlihatkan adanya relasi kekuasaan yang tidak setara antara pihak atasan dengan bawahan. Seperti halnya pada novel SdRS (Suropati dan Robert Anak Suropati) karya Abdoel Moeis yang menceritakan mengenai kehidupan budak di keluarga Tuan edeleer Moor. Budak-budak atau kuli bawahan yang sesungguhnya memiliki martabat sebagai manusia telah diperlakukan tidak manusiawi. Penyiksaan, penghinaan, dan perlakuan lainnya yang tidak manusiawi adalah cara-cara Belanda menghilangkan identitas pribumi sebagai manusia.

Peristiwa perbudakan padazaman penjajahan kolonial memposisikan adanya kelas superioritas dan inferioritas dari pihak kolonial. Melalui perempuanperempuan pemetik teh, orientalisme itu terbentuk. Belanda memandang bahwa pribumi adalah bangsa budak. Dalam konteks itu, mengkontruksi sebuah wacana sebagaimana dominatif yang dimilikinya walau dalam situasi dan kondisi apapun bahwa budak/pribumi adalah makhluk yang selalu berada di bawah majikan (Belanda). Sebagaimana kutipan berikut.

"Bagi yang tidak mengetahui, senyum pemetik itu ibarat lambaian mesra tangan yang penuh kasih, membuat orang ingin mendekat dan menyapanya. Secara tidak langsung, para pemetik itu telah dijadikan bintang promosi. Sebagai daya tarik supaya orang mau menikmati produksi teh dari perkebunan. Padahal dirinya merasakan dunia pemetik adalah dunia yang keras. Di mana perempuan mejadi budak. Menjadi kuda. Menjadi mesin. Peduli gerimis serta dingin menggigit tulang, tak ada pemetik yang berani beranjak sebelum perintah pulang diberikan." (Santosa, 2002: 17)

Deskriptif tersebut menunjukkan hibriditas dari pihak majikan/atasan yang sebenarnya sama-sama penduduk pribumi, akan tetapi mempunyai pemikiran yang sama dengan kolonial. Peniruan identitas kolonial tentunya semakin memperkuat stereotip yang ditujukan pada pribumi yang diwakili oleh pemetik teh. Kuli petik teh dijadikan seperti budak. Tidak mendapatkan hak yang sesuai dengan semestinya. Dalam perspektif postkolonial, konstruksi wacana yang dibangun adalah wacana kolonial yang memberikan stereotip bahwa pribumi adalah pasif. Hal tersebut terbukti bahwa para pemetik tidak akan berani beranjak sebelum diperintahkan untuk pulang. Pandangan bahwa pribumi pasif menandakan bahwa kolonial adalah pihak yang aktif. Aktif lebih baik dari asif. Binerisme ini mencerminkan adanya kelas atas dan kelas bawah.

Selain itu, kolonial atau Belanda juga memberikan stereotip-stereotip seperti boneka kepada pribumi. Pribumi digambarkan seperti barang yang mudah dipermainkan oleh majikannya. Berikut kutipan yang mendeskripsikan hal tersebut.

"Benarkah seperti itu pesona pemetikan dengan perempuanperempuan gunung yang 
lugu? Tidak! Sekali lagi, tidak. Semuanya itu hanya tipuan, hanya semu. Penipu terhadap kenyataan yang selama ini disembunyikan. Mereka seperti hidup dalam pingitan. Disanjung dalamsetiap pembicaraan, namun kesehariannya diinjak-injak nasibnya tak ubahnya boneka. Mudah dilempar kesana-kemari sesuka pemiliknya"(Santosa, 2002: 16).

Berdasarkan pada kutipan tersebut menunjukkan dominasi, penindasan, dan memberikan identitas bagi pribumi. Pada pandangan yang sudah dibuat bahwa pribumi bodoh, irasional, malas, dan menghamba, menumbuhkan kekuatan-kekuatan baru bagi Belanda dalam upaya menaklukan pribumi. Seperti halnya dengan deskripsi pada kutipan novelet Dorodasih yang mengambarkan ketidakadilan. Kaumkaum perempuan yang termajinalkan karena statusnya sebagai buruh rendahan.

"Dasih diam saja. Wajahnya tak berubah. Dingin tanpa ekspresi. Kendati batinnya berkutat habishabisan menahan perasaannya yang mulai bergejolak." (Santosa, 2002: 15)

Melalui tokoh utama yang bernama Dorodasih atau Dasih dapat terlihat dengan jelas perbedaan antara bawahan dan atasan. Kutipan diatas memberikan penjelasan ketidak berdayaan kaum inferioritas atas halnya status sosial. Sungguh pun yang terdapat pada kutipan tersebut menandakan keinginan tokoh Dasih untuk berbicara. Akan tetapi, hanya dipendam. Hal demikian menandakan adanya peniruan pada masa penjajahan yaitu kaum budak tidak diperkenankan untuk berbicara. Hanya diam dan menuruti apa yang diinginkan oleh kaum superioritas. Berikut pula kutipan yang mengambarkan betapa susah dan keterpaksaan buruh rendahan yaitu pemetih teh.

"Mata Dasih mendadak panas. Ada bulir-bulir airmata yang tiba-tiba mendesak ingin keluar. Mau rasanya ia menangis. Bukan menangisi dirinya, melainkan pedih menyaksikan senyum pemetik pada kalender tadi. Kapankah pemetik dapat sungguh-sungguh tersenyum seperti itu? Tersenyum sampai ke hati, bukan sekadar tuntutan fotografi. Benar-benar tersenyum bahagia lantaran pekerjaannya mampu memberikan berkah setara dengan jerih lelah yang diberikannya kepada perusahaan" (Santosa, 2002: 17).

Pada kutipan tersebut melalui pikiran Dasih bahwa pemetik teh yang mayoritas perempuan dijadikan sebagai alat seperti benda mati tanpa daya dan upaya. Mengikuti apa yang disuruh oleh atasan. Jelas terlihat pada kalimat, " Kapan pemetik dapat sungguh-sungguh tersenyum seperti itu? Tersenyum sampai ke hati, bukan sekadar tuntutan fotografi." Artinya dibalik wajah para pemetik teh yang ceria terdapat keterpaksaan. Keterpaksaan buruh petik teh yang mendapat upah tak seberapa dibandingkan dengan tenaga yang harus dikeluarkannya.

Berdasarkan konteks tersebut, hibriditas kolonial jelas terlihat. Para atasan sebagai perwakilan masyarakat 
pribumi bertindak dalam bekerja seperti koloni. Peniruan yang dilakukan oleh para atasan mengakibatkan adanya relasi yang tidak setara. Relasi yang muncul yaitu adanya relasi yang tidak setara antara majikan dan para budak. Para budak atau buruh secara psikis tersiksa dan suara tangis para kuli tidak dipandang lagi sebagai jeritan kemanusiaan karena kaum majikan/ atasan tidak mau mendengar suarasuara mereka. Sehubungan dengan hal tersebut, pada novelet Dorodasih karya Imam Budhi Santosa terdapat tokoh Temo Kasman sebagai bapak dari Dorodasih. Ketika Dasih mengalami masalah terkait dengan pelanggaran yang dilakukannya ada konteks yang menunjukkan kedudukan dari pemetik teh. Berikut kutipan yang memperlihatkan betapa rendahnya posisi pemerik teh.

"Masa depan itu artinya, ya kehidupan yang lebih baik. Bisa naik pangkat, gaji bertambah, status berubah. Kalau pemetik dari dulu nasibnya ajeg seperti itu itu saja. Lihat Mbok Wagi, Mbah Rubi. Petiknya baik. Toh sampai nini-nini, sampai ubanan, tetep jadi tukang petik melulu. Kehidupannya coba? Ada perubahan, apa? Itu semua karena pemetik itu tidak menjanjikan apa-apa kepada kita, selain upah." (Santosa, 2002: 26)

Kutipantersebutmemperlihatkan bahwa Temo Kasman mempertanyakan mengenai posisi pemetih teh. Selain itu, kedudukan sebagai kuli rendahan yang nasibnya sampai kapan pun akan tetap sama. Hanya menunggu jatah upah yang dihasilkan perharinya. Dari deskripsi tokoh Temo Kasman tidak ada penghargaan bagi buruh rendahan. Hasil keringat yang dikeluarkan tidak sebanding dengan apa yang diterimanya. Kembali teringat dengan masa penjajahan bangsa Indonesia yang dijajah salah satunya yaitu kaum koloni. Betapa menderitanya dan sengsaranya penduduk Indonesia. Lahan, tenaga dan hasil bumi dirampas begitu saja. Tidak ada rasa peduli atau kasihan melihatnya. Kembali rasa kemanusiaa itu dipertanyakan. Melalui novelet Dorodasih karya Imam Budhi Santoso secara tidak langsung dapat dilihat sistem kerja rakyat pribumi yang meniru dan bergaya kekoloni-kolonian. Sadar atau tidak disadari atau bahkan sudah masuk pada pola pikir yang terus menerus mengakar ke dalam alam pikir pribumi. Tokoh-tokoh yang dihadirkan oleh penulis yaitu Imam Budhi Santosa terutama para atasan dari perkebunan teh mengingatkan kembali pada masa penjajahan.

"Nduk, apa cita-citamu itu dapat terlaksana? Tidak berbahaya bagi dirimu dan bapak? Ingat Sih, kita ini tinggal diperumahan karyawan. Jangan sekalisekali merongrong majikan. Salah-salah dapat diusir. Kalau sudah demikian, kita mau tinggal dimana?" Kendati nada bicaranya seperti menakutnakuti, namun Temo sebenarnya ingin menguji. Apakah cita-cita tersebut telah merasuk ke dalam sanubari Dasih atau baru anganangan belaka." (Santosa, 2002: 27)

Dalam konteks peristiwa 
tersebut, Temo kembali menyadarkan kepada Dasih bahwa posisinya hanyalah buruh rendahan. Berdasarkan pandangan Temo Kasman, wacana Barat yang berlindung di balik Timur sebagaimana dikatakan Said (1978: 3) terkonstrusi bahwa Barat ingin mengusai seutuhnya. Bukan hanya wilayahnya tetapi, akan pikiran pribumi yang merasa dirinya tidak mempunyai kekuatan apapun. Tidak berdaya dan berada diposisi paling bawah. Cara ini adalah tindakan cerdik yang dilakukan penjajah dari Belanda dalam upaya menguasai pribumi. Dengan menjadikan Timur (pribumi) dibawah kekuasaan Belanda, ia akan lebih mudah menguasai, memiliki, memerintah, bahkan menaklukan. Hal tersebut sudah terbukti dan nampak pada perilaku pribumi yang diwakili oleh tokoh Ponco dan para atasan lainnya. Berikut kutipan yang memperlihatkan peniruan identitas kolonial.

"Oh ya, nanti kalian yang wajarwajar saja. Jangan dibuat-buat. Biasa seperti ini. Santai, nggak tegang. Kalau nggak diminta jangan melihat kamera. Sebentar maaf ya. Itu yang baju merah, namanya siapa?

"Dasih Pak, Dorodasih lengkapnya," sahut Ponco

"Ya, Dasih. Bagaimana kalau ganti baju? Bisa? Pakai yang tidak menyolok, gitu? Biar ada keseragaman dengan yang lain. Bagaimana? Bisa kan?" (Santosa, 2002: 10)

Dari kutipan tersebut dapat terlihat peniruan atau hibriditas kolonial pada tokoh Ponco. Peniruan itu terdukung dengan deskripsi pemikiran tokoh Ponco yang mengharuskan Dasih memakai pakaian yang tidak menyolok. Pemikiran Ponco merepresentasikan sosok koloni yang pada penjajahan mengharuskan pribumi mengikuti segala perintah atasan. Seakan semuanya diatur oleh atasan. Betapa mirisnya pola pikir pemimpin yang memerintahkan pekerjanya dengan menggunakan pemikiran-pemiran koloni. Pengaturanpengaturan yang disampaikan tokoh Ponco mulai dari cara memandang hingga berbusana memposisikan buruh petik teh seperti peliharaan. Tidak mempunyai hak untuk berpendapat dan kaum atasan lebih bersikap memaksakan kehendaknya.

Dengan demikian, hibriditas pada novelet Dorodasih karya Imam Budhi Santosa memperlihatkan dominasi pemikiran kolonial. Pendominasian cara berpikir kolonial terlihat berdasarkan penulis mendeskripsikan situasi dan posisi pemetik teh dalam sistem kerja perkebunan. Hal tersebut lantaran bekas-bekas penjajahan kolonial yang ditiru oleh pribumi. Selain itu, realitanya memang tidak dapat dipungkiri bahwa bangsa Indonesia mengalami penjajahan hingga ratusan tahun, sehingga peninggalan kolonial yang sampai saat ini nyata adalah relasi kekuasaan majikan terhadap pekerjanya.

\section{Pendidikan Karakter}

Tujuan nilai pendidikan karakter dalam novel secara umum adalah untuk menanamkan nilai pendidikan karakter anak ke arah yang lebih baik. Pendidikan karakter sangat penting diberikan kepada peserta didik sebagai generasi yang akan melanjutkan tonggak perjuangan masa depan. 
Pendidikan karakter ini menunjukkan tingkah laku seorang individu atau kelompok yang menjunjung tinggi budi pekerti. Sementara itu, peran sastra dalam membentuk generasi yang akan datang diharapkan dapat terealisasi. Oleh karena itu, orang tua dan guru wajib membimbing perkembangan peserta didik ke arah yang positif agar menjadi anggota masyarakat yang berguna. Salah satu sarana untuk mencapai tujuan tersebut adalah sastra yang sesuai dengan perkembangan peserta didik.

Berdasarkan hasil temuan
penelitian, terdapat nilai-nilai
pendidikan karakter yang terkandung dalam novelet Dorodasih karya Imam Budhi Santosa sesuai dengan Pusat Kurikulum Kementerian Pendidikan Nasional (2010: 9-10). Nilai-nilai pendidikan karakter yang mendominasi yaitu kerja keras. Kerja keras yakni perilaku yang menunjukkan upaya secara sungguh-sungguh (berjuang hingga titik darah penghabisan) dalam menyelesaikan berbagai tugas, permasalahan, pekerjaan, dan lain-lain dengan sebaik-baiknya. Kerja keras harus diimbangi dengan sifat tekun agar seseorang tidak mudah goyah dan putus asa dalam mengerjakan apa yang dilakukan. Tidak putus asa apabila pekerjaannya mengalami suatu hambatan.

Selain itu, kerja keras juga dapat memenuhi kepuasan jiwa seseorang terlebih lagi jika yang dikerjakan mendapat hasil yang diinginkan. Seorang pekerja keras akan memiliki motivasi yang lebih serta tujuan yang jelas terhadap suatu yang sedang dikerjakan. Nilai tentang kerja keras menjadi dominasi yang ditemukan dalam novelet Dorodasih. Berikut salah satu kutipan yang mendeskripsikan nilai pendidikan karakter kerja keras.

"Tapi bagi Dasih, juga pemetikpemetik lainnya, cuaca seperti ini bukan gangguan yang berarti. Dingin, gerimis, angin, dan kabut sudah merupakan sahabat. Teman setia menjelajahi daratan-daratan sunyi setiap hari. Saksi utama ketegaran mereka menapaki kerasnya kehidupan di bumi leluhur sendiri". (Santosa, 2002: 16)

Nilai pendidikan karakter pada aspek kerja keras diperlihatkan oleh tokoh utama yang bernama Dorodasih atau Dasih dan pemetik-pemetik perempuan lainnya. Kegigihannya dalam menjalani hidup dapat dijadikan untuk terus memotivasi diri agar apa yang diinginkan dapat terwujud. Hal ini senada dengan yang telah diuraikan oleh Kementerian Pendidikan Nasional (Kemendiknas, 2010: 9) bahwa kerja keras merupakan sikap sungguh-sungguh dalam mengatasi dan menyelesaikan berbagai tugas. Dengan demikian nilai pendidikan karakter yang mendominasi pada novelet Dorodasih karya Imam Budhi Santosa adalah kerja keras.

\section{Kesimpulan}

Hibriditas kolonial yang muncul pada novelet Dorodasih karya Imam Budhi Santosa memperlihatkan posisi pribumi sebagai masyarakat terjajah. Kekuasaan penjajah atas pikiran, perasaan, sikap, dan perilaku dapat tertanam sangat dalam sehingga 
tetap mempertahankan pengaruhnya bahkan ketika masyarakat terjajah justru berusaha untuk membebaskan dirinya. Hal tersebut karena strategi penanaman kekuasaan yang kamuflatif dan manipulatif yang dapat digunakan untuk mengubah kekuasaan seakanakan menjadi kebaikan. Akan tetapi, munculnya semangat para masyarakat bekas jajahan yang tetap mencerminkan karakter kerja keras dalam menjalani kehidupannya. Nilai karakter kerja keras mendominasi dalam novelet Dorodasih karya Imam Budhi Santosa.

\section{Daftar Pustaka:}

Aunillah, Nurla Isna. 2011. Panduan Menerapkan Pendidikan Karakter di Sekolah. Yogyakarta: Laksana.

Barry, Peter. 2010. Beginning Theory: Pengantar Komprehenssif Teori

Kemendiknas. 2010. Pengembangan Pendidikan Budaya dan Karakter Bangsa. Jakarta: Badan Penelitian dan Pengembangan Kurikulum

Nurgiyantoro, Burhan. 2005. Teori Pengkajian Fiksi. Yogyakarta: Gadjah Mada University Press.

Ratna, Nyoman Kutha, 2008. Sastra dan Culture Studies: Representasi Fiksi dan Fakta. Yogyakarta: Pustaka Pelajar.

Ryan, Michael. 2007. Teori Sastra: Sebuah Pengantar Praktis. Yogyakarta: Jalasutra.

Santosa, Imam Budhi. 2002. Dorodasih. Yogyakarta: Pustaka Sasstra LkiS Yogyakarta.

Suyadi. 2013. Strategi Pembelajaran
Pendidikan Karakter. Bandung : Remaja Rosdakarya.

\section{Lampiran}

1. Identitas Buku

Nama buku : Dorodasih

Pengarang : Imam Budhi

Santoso

Jumlah halaman $\quad: x+294$

halaman, $12 \mathrm{x}$

$18 \mathrm{~cm}$

Tahun terbit $\quad: 2002$

Penerbit : Pustaka Sastra

LkiS

Kota terbit : Yogyakarta

Warna cover : Hijau

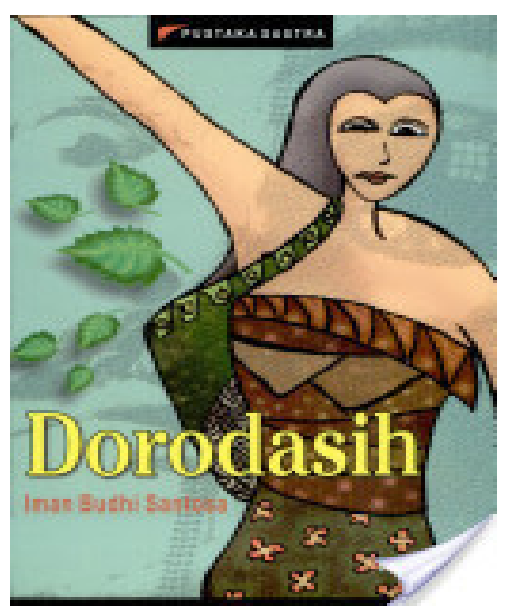

2. Unsur Pembangun Karya Sastra

a. Unsur intrinsik novelet Dorodasih

1) Novelet ini bertemakan ketegaran dalam sosok perempuan yang bernama Dorodasih. Pengarang dalam novelete ini secara gambling memaparkan isi dari karyanya. Sebagaimana pada kutipan berikut. 


“Tapi bagi Dasih,
juga pemetik-pemetik
lainnya, cuaca
seperti ini bukan lagi
gangguan yang berarti.
Dingin,gerimis,angin
dan kabut sudah
merupakan sahabat.
Teman setia menjelajahi
dataran-dataran sunyi
setiap hari. Saksi utama
ketegaran mereka
menapakir kerasnya
kehidupan di bumi
leluhur sendiri“.
halaman 3)

“Mas y a r a k a $t$ Kembangsari tak ada yang menyangka Dasih benar-benar memilih bekerja sebagai pemetik teh biasa. Pagi absen ke pabrik. Kemudian berdesak-desakan di atas truk yang membawa ke kebun. Siangnya bersahutsahutan nembang untuk mengobati lelah manakala matahari berpijak di atas kepala. Mau berebut gula jawa dengan sesama pemetik jika kebetulan miliknya telah habis". (halaman 7)

2) Dalam novelet Dorodasih penullis menggunakan alur campuran. Berikut kutipannya.

$\begin{array}{lr}\text { "Sudah } & \text { seminggu } \\ \text { Darsih menjani masa }\end{array}$

skorsingnya. Selama itu baru sekali ia berpergian meniggalkan kebun. Ke pasar belanja kebutuhan dapur yang persediaannya telah menipis. Setelah itu tidak kemana-mana. Di rumah saja...........". (halaman 23)

3) Penulis juga menggunakan beberapa gaya bahasa untuk memperindah isi cerita. Misalnya pada kalimat 'Air mukanya memancarkan ketabahan'. (halaman 14) Termasuk gaya bahasa atau majas hiperbola karena melebih-lebihkan sesuatu yang tidak mungkin kebenarannya. Selain itu terdapat juga majas lain yang terlihat dalam kalimat 'senyum pemetik itu ibarat lambaian mesra tangan yang penuh kasih'. (halaman 16) Termasuk majas perumpamaan karena mengibaratkan suatu hal yang tidak mungkin terjadi.

4) Sudut pandang yang digunakan oleh penulis adalah sudut pandang orang ke tiga pelaku utama. Karena dalam cerita tersebut menggunakan nama orang sebagai subjeknya. Dorodasih adalah nama yang dipilih pengarang sebagai tokoh utama dalam cerita. Berikut kutipan dalam novelet.

"Bapak bilang apa?
Saya takut? Iya, Pak?
Dorodasih takut
menghadap Pak Sinder?


Jawab Dasih sambil memeluk pundak bapaknya. Suaranya terdengar merajuk. Pipi Temo yang mulai keriput diciuminya". (halaman 23)

5) Setting yang terdapat pada cerita adalah setting tempat, waktu, dan suasana. Setting tempat yang terlihat antara lain: perkebunan teh, lereng bukit Sewarung, kantor Afdeling dan lain-lain. Setting waktunya adalah pagi dan siang. Sedangkan setting suasana yang ada antara lain: langit cerah, damai pada pegunungan yang sunyi, dan sebagainya.

a) Kutipan yang menunjukkan setting tempat salah satunya sebagai berikut.

"Dasih berdiri. Menghormat. Kemudian melangkah ke pintu. Di luar, pemetikpemetik baru pulang. Berbondong-bondong ke pabrik. Diantara mereka tampak mandor Ngusman dan mandor Ponco. Tahu Dasih keluar dari kantor Afdeling, mereka mengisyaratkan sesuatu. Tapi Dasih tak menggubrisnya". (halaman 21)

b) Kutipan yang menunjukkan settinng waktu sebagai berikut.

"Hari masih pagi.
Lonceng pabrik baru saja berkeleneng enam. Udara berkabut. Langit kelabu. Angin mendesau sesekali. Meninggalkan desir lembut pada hamparan perdu teh yang membentang bagai permadani hijau menyelimuti bukit lembah Perkebunan Kembangsari ". ( halaman 3 )

c) Kutipan yang menunjukan suasana sebagai berikut.

"Tapi bagi Dasih, juga pemetik-pemetik lainnya, cuaca seperti ini bukan lagi gangguan yang berarti. Dingin,gerimis, angin dan kabut sudah merupakan sahabat. Teman setia menjelajahi dataran-dataran sunyi setiap hari. Saksi utama ketegaran mereka menapaki kerasnya kehidupan di bumi leluhur sendiri ". ( halaman 3)

6) Pendeskripsian watak tokoh secara analitik yaitu penulis dalam novelet ini secara langsung menerangkan karakter atau tokoh utamanya yaitu Dorodasih yang mempunyai watak keras hati, baik dan berbudi luhur, selain itu sederhana dalam menjalani hidupnya. Kutipannya sebagai berikut.

“Anak itu keras hatinya. 
Tetapi orangnya baik. Luhur budinya... (halaman 13)

7) Pencitraan dalam novelet iini ada tiga yaitu pencitraan visual, audio, dan audio visual.

a) Kutipan yang menunjukkan citraan penglihatan ( Visual ) sebagai berikut.

"Dasih berdiri. Me $n g h$ or $m$ a $t$. Kemudian melangkah ke pintu. Di luar, pemetik-pemetik baru pulang. Berbondongbondong ke pabrik. Diantara mereka tampak mandor Ngusman dan mandor Ponco. Tahu Dasih keluar dari kantor Afdeling, mereka mengisyaratkan sesuatu. Tapi Dasih tak menggubrisnya". (halaman 21)

b) Kutipan yang menunjukkan citraan pendengaran ( Audio ) sebagai berikut.

"Hari masih pagi. Lonceng pabrik baru saja berkeleneng enam. Udara berkabut. Langit kelabu. Angin mendesau sesekali. Me ning galkan desir lembut pada hamparan perdu teh yang membentang bagai permadani hijau menyelimuti bukit lembah Perkebunan Kembangsari “. ( halaman 3 )

c) Kutipan yang menunjukan citraan perasa sebagai berikut.

"Tapi bagi Dasih, juga pemetik-pemetik lainnya, cuaca seperti ini bukan lagi gangguan yang berarti. Dingin,gerimis, angin dan kabut sudah merupakan sahabat. Teman setia menjelajahi dataran-dataran sunyi setiap hari. Saksi utama ketegaran mereka menapaki kerasnya kehidupan di bumi leluhur sendiri ". ( halaman 3)

8) Amanat yang terkandung dalam novelet ini bahwa setiap manusia wajib berusaha, selain ikhtiar juga tawakal yang perlu diperhatiakn dalam menjalani kehidupan. Kita juga jangan pernah meremehkan kedudukan perampuan, karena dari tangan para perempuanlah peranan laki-laki dapat terbantu. seperti kutipan berikut.

"Semenjak dulu
kala, mati hidupnya
perkebunan




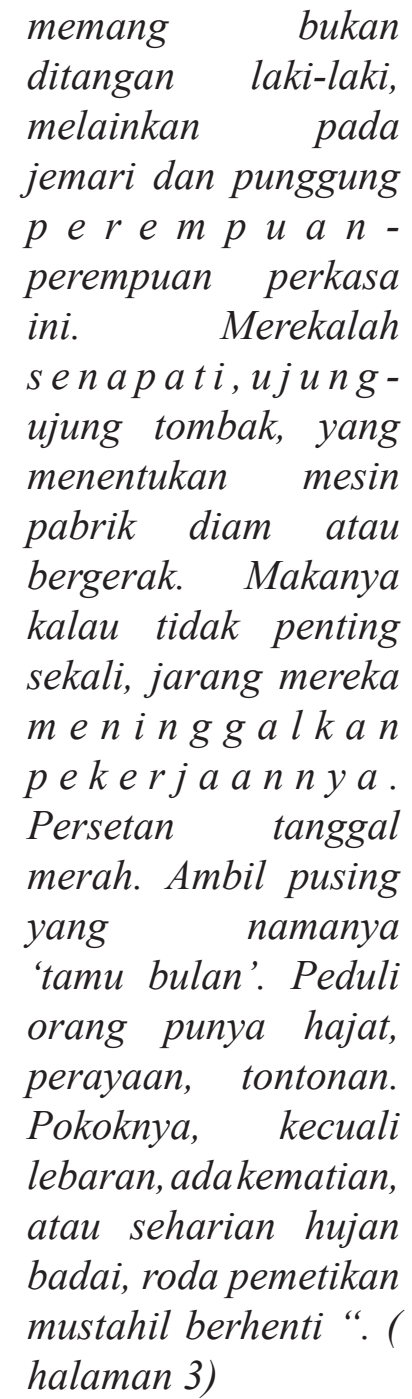

b. Unsur-unsur ekstrinsik dalam novelet ini meliputi biografi pengarang dan norma-norma dalam masyarakat.

1) Berikut biografi pengarang.

"Imam Budhi Santoso, lahir di Magetan, 28 Maret 1948. Pernah bekerja di perkebunan teh di Kendal, Semarang. Kemudian masuk Dinas Perkebunan Prop. Dati 1 Jawa Tengah. Tahun 1987 mengundurkan diri. Kini bekerja sebagai penulis freelance di Yogyakarta.
Pada tahun 1969 ikut mendirikan Persada Studi Klub (PSK) bersama Umbu Landu Peranggi cs. di Mingguan Pelopor Yogya.

Bukunya yang telah terbit: Ranjang Tiga Bunga (novel, 1975), Barang Keertapati (novel, 1976), TigaBayangan (puisi, 1970). Puisinya terdapat dalam antologi: Tugu (1986), Tonggak 3 (1987), ZamrudKhatulistiwa (1997), Gerbong (1998). Mengeditori antologi puisi Sembilu (1991), Ambang (1992), antologi esei sastra Begini, Begini, Begitu (1997), dan Tamansari (1998). Eseinya diterbitkan oleh Puspa Swara dalam Senandung Rumah Ibu (1993). Cerpennya ada dalam antologi Lukisan Matahari (Bernas, 1993). Memenangkan lomba penulisan puisi TBY 1994 Seorang Buta dan Kemenangan Seorang Buruh Harian (LirikLirik Kemenangan, 1994). Memenangkan Lomba Penulisan Cerkak TBY 1998 (Liong TembangPrapatan)

Menjabat Ketua Seksi Sastra Indonesia pada Festifal Kesenian Yogya (FKY) tahun 1995, 1997, 1998. Tulisan dan puisinya dipublikasikan di majalah Horison, Basis, Citra Yogya, Antologi PPIA Surabaya, serta lembar kebudayaan media massa 
pusat dan daerah. ". ( halaman 293-294).

2) Nilai-nilai yang terkandung dalam novelet ini yaitu nilai moral dan sosial.

a) Kutipan berikut memaparkan mengenai nilai sosial.

“ Mendenga rjawaban Temo yang terus terang menyebut pemetik itu kuli, Dasih tertawa. 'Itulah yang menjadi cita-cita saya, Pak. Bagaimana membuat pemetik-pemetik itu bukan lagi kuli. Paling tidak supaya mereka diperhatikan".( halaman 26)

b) Nilai moral yang terdapat dalam novelet ini sebagai berikut.

"Ketikadengan Ponco bertambah intim. Ruwanti pernah rerasanan ingin menjebaknya, disamping memang jatuh cinta beneran dengan Ponco. Jelasnya, agar enanggungjawabijanin yang andungnya....".(halaman 85) 